\title{
Psychiatry in Jordan
}

\section{Adnan Takriti}

Editor-in-Chief, Arab Journal of Psychiatry, Consultant Psychiatrist, PO Box 5370, Amman 11183, Jordan, email takriti@nets.com.jo

ordan, one of the most recently established countries in the Middle East, was part of the Ottoman Empire. It was declared a political entity known as Transjordan under the mandate of the British government in 1923, until it gained independence and was declared a Kingdom in 1946. In 1950, Transjordan and the West Bank were united and assumed the current name of the H ashemite Kingdom of Jordan. The next major change for the Kingdom came in 1967, when the occupation of the West Bank and Gaza Strip by Israeli forces caused a massive influx of migrants to the East Bank.

Jordan has a total area of $89342 \mathrm{~km}^{2}$ and a population of 5329000 (2002 statistics). The gross domestic product (GPD) per capita is US\$1765. The illiteracy rate (among those aged over 15 years) is $10.3 \%$ (5.4\% for males and $15.2 \%$ for females). Life expectancy at birth is 71.5 years and the infant mortality rate is 22.1 per 1000 births. The unemployment rate is $15.3 \%$.

The M inistry of $\mathrm{H}$ ealth budget is $5.7 \%$ of total spending. There is one hospital bed for every 568 citizens and one psychiatric bed for every 9000 . There is one physician for 600 citizens and one psychiatrist for every 75000 .

\section{Evolution of psychiatric services}

At the time of the British mandate in Palestine in 1915, all psychiatric services were obtained from Palestine. The only psychiatric hospital (in Bethlehem) was in Palestine. In the late 1950 s a visiting psychiatrist from Bethlehem hospital used to attend an out-patient psychiatric clinic once a week. Three separate streams of evolution occurred subsequently, in the armed forces, in the Ministry of $\mathrm{H}$ ealth and in academic psychiatry.

Psychiatric services in the armed forces

In the early 1960s there was only one psychiatrist, who had been trained at the Maudsley H ospital in London. In 1966 a department of psychiatry was established within the main military psychiatric hospital, in Marka, Amman, the capital city. A graduate training programme was implemented, which was recognised by the British Medico-Psychological Association.

In 1973 the King Hussein Medical Centre was founded and its psychiatric department was established in 1975. However, in 1997 it was transferred to its original place in the Marka hospital; this was considered a setback and a failure on the part of medical administrators to understand the need for a multi-disciplinary approach to psychiatry.

Currently there are 12 qualified psychiatrists who run psychiatric services in the armed forces; most of them were trained in Britain.

Psychiatric services provided by the Ministry of Health

The need for a psychiatric hospital became apparent after the 1967 war with Israel, when the West Bank fell under occupation. In April 1987 the $\mathrm{N}$ ational Centre for Mental $\mathrm{H}$ ealth was established, with 300 beds. In addition, 150bed hospitals were established for patients with chronic illness and for rehabilitation. Recently, a centre for the treatment of drug addiction was established, with 46 beds.

There are 30 out-patient clinics throughout the country, which are attended by 33000 patients annually. There are currently only 8 psychiatrists providing this service, largely because neighbouring Saudi Arabia, which can afford to pay higher salaries, draws many health professionals away from Jordan.

\section{Academic psychiatry}

There are two medical schools in Jordan, at the University of Jordan, in Amman, and at the University of Science and Technology, in the town of Irbid in northern Jordan. Medical students undergo 1 month of training in the government psychiatric hospital in their 5th year. There is no psychiatric department at the U niversity of Jordan, although there are two psychiatrists working at its out-patient clinic. Recently, the U niversity of Science and Technology established a psychiatric unit (with 30 beds) in the newly built university hospital. U ndergraduate and graduate programmes are being established.

\section{Psychiatric journals}

The Arab Journal of Psychiatry is published biannually under the auspices of the Arab Federation of Psychiatrists. It is published in Jordan although it represents all Arab psychiatrists.

\section{The private sector}

There are 30 private psychiatrists who work exclusively in their own clinics. Psychiatrists in the public sector, described above, are not allowed to work privately. There is one psychiatric hospital, with 70 beds, which serves psychiatrists in the private sector.
Contributions to the country profile section are welcome: please contact Shekhar Saxena (email saxenas@who.int).

There are 30 outpatient clinics throughout the country, with 33000 patients attending annually. There are currently only 8 psychiatrists providing this service, largely because neighbouring Saudi Arabia, which can afford to pay higher salaries, draws many health professionals away from Jordan. 


\section{Psychiatric treatments}

Trends in psychiatric treatments in Jordan have run parallel to those in Britain, largely because many of the country's psychiatrists have trained in Britain since the early 1960s. Accordingly, tricyclic antidepressants, monoamino oxidase inhibitors and conventional neuroleptics were used. More recently, since the late 1980s, the new generation of antidepressants (e.g. the selective serotonin reuptake inhibitors) and novel antipsychotics have been extensively prescribed. Mood stabilisers, including lithium and various anticonvulsants, are available. Electroconvulsive therapy, abreactive techniques and hypnosis are also used. Psychotherapy is being practised by some psychiatrists who were trained in specialised centres in the UK and USA, generally in the field of cognitive-behavioural therapy; psychodynamic therapies are not practised in Jordan.

Group therapy, occupational therapy and rehabilitation are usually practised for in-patients.

\section{Educational issues}

The universities have their own undergraduate syllabus. Postgraduate teaching is accredited under the auspices of the Jordan Medical Council, which is the medical body that deals with all academic issues. The Council has a psychiatric division that steers the theoretical and clinical aspects of psychiatry. After a 4-year training programme, which covers basic sciences and clinical experience, the candidate sits the psychiatric board examination.

\section{Professional body}

The Jordan Psychiatric Association is a division of the Jordan Medical Syndicate. There are 60 registered psychiatrists.

\section{Fields allied to psychiatry}

C linical psychologists, social workers and occupational therapists, in addition to psychiatric nurses, are part of the psychiatric teams in the psychiatric hospitals and departments. Generally speaking, there is always a lack of adequate staffing in all these fields, as in psychiatry. There is a Psychological Association run by psychologists, which is licensed by the Ministry of $\mathrm{H}$ ealth. Some members of the Association run clinics in the field of counselling psychology. Unfortunately, there is no collaboration with psychiatrists, at any level.

\section{The M ental Health Act 2003}

The Act provides for the compulsory admission of psychiatric patients, who include those with a drug addiction (to narcotics or psychotropic agents). It states the conditions for the admission and discharge of such patients. The following are notable sections.

\section{Section 15}

A general hospital can allocate a department for psychiatric patients provided that it has on its staff one or more psychiatrists, as well as the required numbers of resident doctors and specialised staff.

\section{Section 16}

Section 16A states that psychiatric patients may be admitted to either a psychiatric hospital or a psychiatric department of a general hospital either voluntarily or compulsorily in the following cases:

$O$ if the patient or the addict needs treatment that is provided only at these facilities

o if the patient is causing harm to him/herself or others, whether this harm is physical or psychological

$O$ if the patient or the addict is causing damage to property

O if a court of law so decides, in accordance with the medical evidence presented.

Section 16B sets out the following conditions for hospital admission (excepting the last, forensic case above):

$O$ an application must be addressed to the hospital manager

O a medical report must be issued by a psychiatrist in support of the application addressed to the hospital manager

o the hospital manager (or whoever is authorised to act on the manager's behalf) gives approval.

\section{Section 17}

In the case of compulsory admissions, the Minister of Health can refer the patient to a psychiatric committee to examine the reasons for admission. Accordingly, the M inister can decide to discharge the patient or to prevent the patient's admission, except where the patient has been admitted as a result of a court hearing.

\section{Section 18}

The attending psychiatrist must discharge the patient after recovery, with the approval of the hospital manager. The patient's family should be notified about the date and time of the discharge. Where the patient was admitted as a result of a court decision, the court should be notified.

\section{Research and publications}

There are limited funds for research. $\mathrm{N} o$ epidemiological research has been carried out so far in Jordan. Most research work is published locally in one of the two medical journals or in the one psychiatric journal, mainly for the purpose of career progression. The papers mostly address clinical and cultural issues.

\section{Mental health strategy (1988)}

The main goals are:

0 the teaching of psychiatry to general practitioners and paramedical staff

o the extension of psychiatric services to all provinces of the country

0 the appointment of counselling psychologists and social workers to all schools 
o the incorporation of mental health services within primary health care.

A fair portion of this strategy has been implemented. For example:

O by 1995, 100 general practitioners had received training (with notable success), as had 60 paramedical staff

o psychiatrists now cover 36 health centres in Amman, and this programme has been extended to four other muhafazat (governorates)

o psychological counselling centres, staffed by social workers and psychology graduates, have been established in all the main schools in Jordan.

\section{Cultural issues}

Social stigma is quite strong in relation to psychiatric patients and treatments. Consequently, resort is often made to faith healers before or even after visiting a psychiatrist. There is great ignorance about psychiatry in all sectors of society: rich, poor, illiterate and educated. Stigma also affects the status of psychiatry among the other medical specialties. This has restricted progress in the delivery of psychiatric services.

\section{Sources}

Department of Statistics (2002) Population and Family Health Survey. Amman: Department of Statistics.

Ministry of Health (1988) Mental Health Strategy in Jordan. Report to the World Health Organization. Amman: Ministry of Health.

Shuriquie, N. (2003) Military psychiatry - a Jordanian experience. Psychiatric Bulletin, 27, 386-388.

Website

Jordan Medical Council: www.jmc.gov.jo

\section{The mental health care system in Malta}

\section{Susanna Galea ${ }^{1}$ and John Mifsud ${ }^{2}$}

${ }^{1}$ Clinical Lecturer and Specialist Registrar in Addictive Behaviour, Department of Mental Health, St George's Hospital Medical School, London, email sgalea@sghms.ac.uk; Member of the Royal College of Psychiatrists; Member of the Association of Maltese Specialists in Psychiatry

${ }^{2}$ Consultant Psychiatrist, Our Lady of Mount Carmel Psychiatric Hospital, Malta; Honorary Senior Lecturer, Department of Psychiatry, University of Malta, email psy@shadow.net.mt; Member of the Association of Maltese Specialists in Psychiatry

he Maltese Islands are located in the Mediterranean Sea and have a total area of $316 \mathrm{~km}^{2}$. They consist of three inhabited islands - Malta (the largest of the group), Gozo and Comino - and two uninhabited islands - Filfla and Cominotto. Malta is a democratic republic. Since its independence in 1964, Malta has played a more significant part in international relations. It became a member of the Commonwealth, the United $\mathrm{N}$ ations, the World Health $\mathrm{O}$ rganization and several other organisations. In May 2004, Malta also became a member of the European Union.

The organisation and delivery of mental health services, and access to them, are influenced by Malta's sociocultural specifics. Most ( $98 \%$ ) of the Maltese population is $C$ atholic and the Church plays an influential role in Maltese society. It contributes to the Maltese perception of mental illness and its aetiology and consequences, as well as to the nature of presentation and the utilisation of services. It also affects the community support network and rehabilitation. The geographical proximity of the populace and the predominance of the extended family also play a significant role in the perception, nature and progression of mental illness.

\section{Population}

The population of the Maltese Islands in 2002 was recorded at 394 000. Since 1974, the population has grown linearly and in 2001 the natural population growth was estimated at 2.5 per 1000 population (World H ealth 0 rganization, 2003). The total number of births in 2002 was 3805, giving a crude birth rate of 9.7 per 1000 population. In the same year, the total number of deaths was 3031, giving a crude death rate of 7.7 per 1000 population. The main causes of death among the Maltese population are non-communicable diseases, mainly circulatory disease and cancers. The life expectancy at birth in 2002 was 75.8 years for males and 80.5 years for females ( $N$ ational Statistics 0 ffice, 2003; Ministry of Health, 2004a).

\section{The organisation of health care}

The Maltese government provides a free national health service, for which the Minister of $\mathrm{H}$ ealth has overall responsibility. Residents receive comprehensive care, funded from general taxation (M inistry of Health, 2004b). The proportion of M alta's gross domestic product allocated to the health budget is $6.3 \%$. Residents are not obliged to have health insurance in order to be entitled to health
There is great ignorance about psychiatry in all sectors of society: rich, poor, illiterate and educated. Stigma also affects the status of psychiatry among the other medical specialties.
Most (98\%) of the Maltese population is Catholic and the Church plays an

influential role in Maltese society. It contributes to the Maltese perception of mental illness and its aetiology and consequences, as well as to the nature of presentation and the utilisation of services. 